\title{
ECONOMÍA Y ANTROPOLOGÍA, DIÁLOGOS DISCIPLINARES
}

\author{
María Belén Noceti*
}

\section{INTRODUCCION}

Antropología y Economía, dos disciplinas que se entrelazan, desde hace ya más de un siglo, en torno a debates respecto del rol de la organización económica en el funcionamiento de las sociedades humanas.

Desarrollaremos en este espacio una serie de artículos cortos que tiene por fin explicar los ámbitos de discusión entre estos dos campos disciplinares. En este primer recorrido, nos abocaremos a describir la relación entre Economía y Antropología en el surgimiento del área disciplinar de ésta última, hacia fines del siglo XIX y comienzos del siglo XX.

Más adelante, una vez constituía la rama disciplinar denominada Antropología económica, y en el contexto de la crisis ${ }^{1}$ de la antropología como ciencia, analizaremos los trabajos científicos tendientes a explicar las modalidades en que sistemas económicos tradicionales sufrieron cambios al adentrarse violentamente al mundo capitalista. El desarrollo de la antropología económica pasa a estar centrado en las formas en que ocurre la asimilación, la aculturación y los procesos de sincretismo cultural ${ }^{2}$.

\footnotetext{
"Universidad Nacional del Sur, Departamento de Economía, IIESS, mbnoceti@uns.edu.ar- 4595138 int 2727.

${ }^{1}$ La disciplina se ve en la necesidad de redefinir su objeto de estudio una vez que, prácticamente, no existieron más comunidades aborígenes aisladas del mundo capitalista

${ }^{2}$ Se entiende por sincretismo cultural el proceso mediante el cual se generan nuevos modelos culturales, sociales y económicos luego del encuentro de 2 culturas, siendo este proceso signado por mecanismos de resistencia de los grupos subordinados. Diversos ejemplo podrían marcarse entre ellos aquellos derivados de la resignificación de las creencias tradicionales en contacto con el catolicismo
} 
Durante las décadas del 40 y 50 del siglo pasado cobran especial relevancia los trabajos en torno a la antropología de la pobreza (Lewis, 1952), y, por otro lado, aquellos derivados de estudios respecto del comportamiento de las comunidades ante la escasez de recursos (Herskovitz, 1954 y Firth, 1946). Para la misma época se fortalecen análisis dentro de la escuela materialista histórica, focalizados en la antropología rural y del campesinado en tanto formas de resistencia; estas líneas perdurarán como características de la antropología latinoamericana hasta entrados los años 80 (Ribeiro, 1987; Catullo, 1982; Tamagno, 1988) ${ }^{3}$.

La antropología norteamericana realiza un complejo desarrollo de modelizaciones teóricas de organizaciones económicas en tanto sistemas energéticos de in-put y out-put, fuertemente vinculados a la ecología (Lee, 1977; Rapapport, 1980; Meggers, 1973). Los trabajos más importantes se encontraran en contextos de trabajos de campo en Amazonía y en África.

Desde los años 60, pero con gran énfasis durante la década del 70, dentro de la academia anglosajona, toman especial envergadura los famosos debates entre formalistas y sustantivistas en el ámbito de los journals norteamericanos (Polanyi, 1957; Leclair, 1976; Kaplan, 1976).

En los 80 los estudios de Mary Douglas sobre bienes, rituales y riesgo resultarán ejes de discusión, generando una vuelta al estructural funcionalismo. Por vez primera la antropología económica comienza a cuestionarse no ya sobre las estructuras de circulación sino sobre las convenciones al interior de las instituciones que se erigen para generar un tipo u otro de sistema socioeconómico.

La década del 90, finalizando el siglo XX, dará un nuevo vuelco a la Antropología económica. Los análisis se dirigirán esta vez, más que a la producción y la distribución desigual, a la esfera del consumo, en ámbitos de hibridación cultural (García Canclini,1990; Ravello de Castro, 1999). En esta década, además, proliferan los estudios sobre antropología económica en relación con el ritual, la institución y los sistemas convencionales de premio y castigo al interior de las sociedades. El libro de Mary Douglas y de Isherwood (1990), reinstala en el

\footnotetext{
${ }^{3}$ Estos textos serán retomados en próximas notas

${ }^{4}$ Trade and Market en the Early Empires en 1957. El capítulo de Polanyi en el libro "The Economy as an Instituted Process" escrito en compañía de Conrad Arensberg y Harry Pearson, desde allí por vez primera se estableció la escuela substantiviste en antropología económica. Desafiaba la ortodoxia prevaleciente en antropología económica y su aplicación sin reserva de los principios de la economía neoclásica a sociedades que no eran sociedades de mercado.
} 
debate la disputa del bien en la estructura valorativa de los grupos culturales. Más adelante Douglas seguirá profundizando sus estudios en líneas relacionadas con los estudios de riesgo, buscará indagar respecto de las formas culturales a través de las cuales las instituciones de las sociedades construyen sistemas de riesgos desde donde debieran ser leídas las políticas públicas actuales (1996). Enunciando así, en los albores del siglo XXI nos hallamos implicados en una sociedad cuyo control social se basa en complejos sistemas de generación de incertidumbres donde la dupla riesgo-peligro constituye las bases del desarrollo de políticas sociales.

En todas estas especificidades, el diálogo con la Economía es central para el desarrollo de teorías sustantivas que puedan explicar y describir cuáles son los niveles de organización generados por las comunidades para garantizar su supervivencia. Este diálogo nos brinda herramientas teóricas que nos permiten observar analíticamente los discursos e instituciones que se crean para perpetuar tales organizaciones y posibilitar, a su vez, una dinámica cultural heterogénea que se manifiesta en tanto resistencia ante un contexto global homogeneizante. Comencemos pues a describir esta historia de relaciones.

\section{LOS ALBORES DE LA ANTROPOLOGIA ECONOMICA, MIRADAS EVOLUCIONISTAS}

La antropología comienza su desarrollo como ciencia a mediados del siglo XIX, y fuertemente hacia fines del mismo. En este contexto, la disciplina surge de la mano de las ciencias naturales, diversificándose luego hacia las ciencias sociales, pero no abandonando una mirada evolucionista y positivista la cual perdurará hasta entrado el siglo XX.

Las primeras monografías sobre antropología sociocultural fueron desarrolladas por juristas (Lewis Morgan, 1871 ${ }^{5}$; John Mc Lennan, $1865^{6}$; Johan Bachofen, $1861^{7}$; Marx y Henry Maine, $1867^{8}$; Karl Bûcher, $1893^{9}$ ), quienes buscaron explicar las formas institucionales en que las sociedades se organizaban descri-

\footnotetext{
${ }^{5}$ Sistemas de consanguinidad y afinidad en la familia humana

${ }^{6}$ Primitive marriage, Oxford press

${ }^{7}$ El matriarcado: Una investigación sobre el carácter religioso y jurídico del matriarcado en el mundo antiguo

${ }^{8}$ Ancient Law, Manchester press

${ }^{9}$ Die Entstehung der Volkswirtschaft. Ensayo sobre sociedades no mercantiles, el don y la reciprosidad.
} 
biendo distintos tipos de sistemas de parentesco y de derecho. Destacamos aquí la condición de género pues marcará incluso el tipo de explicaciones que darán respecto de la organización socioeconómica de las llamadas comunidades primitivas en aquella época. ${ }^{10}$

En estos trabajos, los autores dedicaron capítulos especiales a una cuestión fundamental para la cultura occidental, el carácter de "la propiedad", y por otro lado el establecimiento de estadíos en el desarrollo de la economía de las sociedades, emulando los estadíos evolutivos darwinianos, con tendencia unilineal y hacia el mejoramiento progresivo de sistemas económicos de las sociedades sobrevivientes, teniendo por fin del progreso el sistema capitalista europeo. Recordemos en este punto las condiciones en las que estos estudios se realizaban, en contextos coloniales, y donde muchos de los antropólogos resultaban funcionarios públicos de tales sistemas; sus discursos legitimaron formas de dominación jurídico-económicas sobre los territorios colonizados.

La antropología de esta época se dedica a estudiar la forma en que evolucionaban las sociedades, preocupada por establecer el momento en que aparece la civilización como forma característica de la vida humana, y a la cual todo grupo humano debía llegar. Los pensadores de la época señalan un único recorrido posible y asumían que el modo de vida europeo era sin duda el sistema civilizatorio por excelencia y el último en la escala del progreso. En el primer estadio ubicaban aquellas sociedades basadas en economías de subsistencia, donde el alimento se aprehendía diariamente, se consumía sin almacenamiento y su consecución requería una organización basada en la división del trabajo por género y edad, delatando el estadio más primitivo y más cercano al ámbito de vida propio de la naturaleza. Posteriormente establecían distintos períodos a medida que aparecían de manera lineal, temporalmente hablando, los siguientes procesos: aparición de la domesticación de plantas y animales, la división del trabajo en función de trabajo intelectual y físico y por estamentos sociales, el almacenamiento del alimento y el desarrollo de complejos sistemas de redistribución. Como el lector podrá observar el eje de organización de los estadíos evolutivos estaba dado por las formas en que se conseguía el alimento en las sociedades bajo estudio.

\footnotetext{
${ }^{10}$ Con el advenimiento de las mujeres al ámbito disciplinar, durante los años 20 (Margaret Mead, Ruth Benedict) aparecerán por vez primera nuevas explicaciones a la organización parental y económica de las comunidades no occidentales.. La condición de género posibilita a las mujeres analizar mundos simbólicos que para los antropólogos hombres resultaban vedados. ya sea por las comunidades en estudio o ya sea por la propia cultural occidental de los mismos antropólogos que se traslucía en sus explicaciones plagadas de presupuestos paternalistas.
} 
"El conjunto de la evolución económica (al menos de los pueblos de la Europa central y occidental), en aquellos lugares donde puede seguirse con una precisión suficiente, se divide, en mi opinión, en tres fases 1) estadio de la economía doméstica cerrada (la producción personal existe sola, la economía no conoce el intercambio); los bienes son consumidos allí donde se producen. 2) Estadio de la economía urbana (producción para unos clientes o periodo de intercambio directo), los bienes pasan directamente del productor al consumidor. 3) Estadio de la economía nacional (producción de mercancías, periodo de circulación de bienes), los bienes pasan generalmente por una serie de economías antes de entrar en el consumo" (Bücher en Godelier, 1976: 85).

Bronislaw Malinowski en 1926 criticará estas visiones considerando que resultan equívocos en la interpretación de los datos. Su trabajo en las Islas Trobriand resultará materia fundante de la Antropología económica. Físico y matemático, nacido en Croacia, Malinowski se doctora en Antropología en Inglaterra en The London School of Economics ${ }^{11}$.

\section{LA ANTROPOLOGIA ECONOMICA COMO RAMA DISCIPLINAR}

II.1 Reciprocidad e intercambio; el caso del Kula

Malinowski realiza sus tesis en torno al modo de vida de los trobiandeses, y específicamente analiza el sistema de intercambio denominado kula. Su tesis se centra en demostrar que este sistema es una institución que enraiza la vida tribal, desde las acciones cotidianas hasta las grandes festividades. El intercambio basado en un sistema complejo de retribución, obligaciones y contratos rige la vida de la tribu. En palabras del etnógrafo:

"El Kula es un tipo de intercambio intertribal de gran envergadura; lo llevan a cabo comunidades que ocupan un amplio círculo de islas y constituyen un circuito cerrado. ...Dos tipos de artículos, y solamente dos, circulan sin cesar en sentidos contrarios a lo largo de esta ruta. En el sentido de las agujas del reloj se desplazan constantemente los artículos de un tipo: los largos collares de concha roja, llamados soulava. En el sentido contrario se desplazan los del otro tipo: los

\footnotetext{
${ }^{11}$ Universidad que será la cuna de la Antropología Británica en la cual se destacarán además figuras como Raymond Firth, Evans Pritchard.
} 
brazaletes de concha blanca, llamados mwali. Siguiendo su propia dirección en el circuito cerrado, cada uno de estos artículos se encuentra en el camino con los artículos de la otra clase y se intercambian unos por otros sin cesar. Todos los movimientos de los artículos kula, todos los detalles de las transacciones, están regulados y determinados por un conjunto de normas y convenciones tradicionales, y algunos actos del Kula van acompañados de ceremonias mágicas rituales y públicas muy complicadas" (Malinowski, 1999; 31) ${ }^{12}$.

El kula está fundado en el mito, respaldado por la ley tradicional y rodeado de ritos mágicos, consiste en una institución alrededor de la cual toda la vida tribal se organiza; implica varias series de transacciones, definidas en coordenadas temporales diferenciales en 10 años de profundidad.

E1 intercambio ceremonial de los dos tipos de artículos, brazaletes y collares, artículos de ornamentación, es el aspecto más importante y fundamental del kula. Pero, asociado a ello y bajo tal pretexto, se encuentran gran cantidad de actividades y aspectos secundarios. La producción de canoas para la expedición kula que llevarán a los socios con sus objetos de intercambio es también una empresa de gran complejidad que comienza ocho meses antes, y la cual involucra además una serie de ritos mágicos para bendecir el viaje. En este proceso de intercambio, se constituyen esferas de comercio secundario, los asociados realizan comercio, cambiando de una isla a otra muchas mercancías útiles e indispensables, ya que con frecuencia no se pueden encontrar en el distrito de origen. En los intercambios intervienen grupos étnicos sumamente diferentes, cultural y físicamente. El kula no es trueque pues responde a una serie de reglamentos totalmente diferentes, el trueque también es practicado por el grupo y se denomina gimwali.

El kula se realiza en fechas periódicas y supone un complejo sistema de crédito, que se funda en la confianza mutua entre los asociados intertribales, los cuales se encuentran unidos de por vida así como sus descendientes. La alianza en el kula supone también la alianza en la guerra, la protección para uno y otra se encuentra en el hogar del asociado.

No todos los hombres realizan kula, sino aquellos que poseen un status importante en la sociedad, si bien toda la comunidad se involucra de alguna manera en el intercambio, y se ven favorecidos, o no, con la transacción de la misma manera que quien efectivamente lo realiza.

${ }^{12}$ Primera publicación fue en Londres en 1922. 
El kula es ante todo movimiento, nadie retiene nunca un artículo kula por mucho tiempo, generalmente un individuo posee un brazalete o un collar kula por no más de dos años, quien se exceda puede ser catalogado de mezquino, lo cual es una ofensa a su comunidad de referencia. Cada individuo ve pasar por sus manos, a lo largo de su vida, una gran cantidad de artículos; y, por otro lado, para que un objeto salga del circuito kula debe ocurrir algo extraordinario; pues "una vez en el kula, siempre en el kula" (Malinowski, 1999:27). Cada artículo circula en una sola dirección, nunca vuelve atrás, nunca se detiene de forma definitiva y, en general, invierte aproximadamente de dos a diez años en dar una vuelta. Un objeto kula supone la retribución de su opuesto de la misma envergadura, es así que se pueden entregar regalos subsidiarios pero con el solo afán de hacer menos larga la espera por la devolución. De esta devolución depende el estatus de quien ofrece y de su gente. Si el artículo que se da como regalo de devolución no es equivalente, el receptor se sentirá contrariado y se enfadará, pero no dispone de medios directos para exigir una reparación, ni para forzar a su asociado o poner fin a la transacción. Malinowski en este punto se pregunta “¿Cuáles son, pues, las fuerzas que en la práctica obligan a los asociados para que se atengan a las reglas del trato?" Encuentra la respuesta en la aparición de un concepto de riqueza y de valor distinto al que opera en las economías europeas.

La propiedad en el kula descansa en la posesión y en el hecho de devolver, "poseer es dar", y en este precepto se funda la riqueza de un hombre y el valor social otorgado a la posesión. Se supone que un hombre que posee un bien kula debe compartirlo, es un don que ha recibido de los espíritus, debe distribuirlo, ser su depositario y su dispensador, debe mostrarlo en su comunidad; pero además está obligado a embarcarse en la tremenda empresa de conseguir un objeto de la misma envergadura para devolver. Mientras más alto el rango, más grande es la obligación de dar.

Quien disfruta de la posesión de un objeto kula adquiere renombre, exhibe su artículo, explica cómo lo ha obtenido y planea a quién piensa dárselo, todo esto constituye uno de los temas favoritos de conversación y habladurías dentro de la tribu. Cada objeto ornamental se reconoce por un nombre propio y supone una historia de pasajes de mano en mano de antepasados, con lo cual implica un constante enriquecimiento de la identidad colectiva.

En síntesis, el kula supone historia oral, construcción de canoas, expediciones marítimas, ritos mágicos, intercambios comerciales, intercambios de dones reciprocidad-, sistema de honor puesto en marcha, alianzas comerciales, matrimoniales, sanguíneas (pues en función de la conveniencia de asociación se arreglan los matrimonios), finalmente resulta un sistema diferencial de deberes y derechos. 
La cuantiosa información etnográfica que Malinowski produjo durante su estancia en las Islas Trobriand por casi 2 años, entre 1915 y 1918, constituyó material de análisis de muchos antropólogos entre ellos, quien de alguna manera comparte su designación como padre de la Antropología económica, el etnólogo Marcel Mauss.

\section{II.2 El don, sistema de prestación total; el caso del Potlatch}

Mauss, filósofo francés, sobrino de Emile Durkheim, escribió, en 1925, su famoso "Ensayo sobre el don", el cual fuera publicado en L'Année sociologique. $\mathrm{Su}$ objetivo fue responder a las siguientes preguntas ¿Por qué en las sociedades primitivas el regalo recibido debe ser obligatoriamente devuelto? ¿Qué fuerza tiene la cosa que se da, que el destinatario debe devolver?

Mauss compiló datos etnográficos respecto de diferentes sistemas de intercambio tribal y desarrolló su tesis sobre la reciprocidad y el don. Comparó sistemas de prestaciones de Melanesia, Polinesia y de Norteamérica con sistemas jurídico-económicos de origen germánico, romano e indoeuropeo. Tomó datos etnográficos de Malinowski en relación al kula, y de Franz Boas ${ }^{13}$ en relación al Potlatch del noroeste de Norteamérica.

Marcel Mauss describió las características de estos sistemas de prestaciones económicas en tanto fenómeno social total, en la medida que involucra diversas dimensiones de la vida comunitaria.

"No son los individuos, sino las colectividades las que se obligan mutuamente, las que cambian y contratan; las personas que están presentes en el contrato son personas morales, clanes, tribus, familias, que se enfrentan y se oponen, ya sea en grupos que se encuentran en el lugar del contrato o representados, por medio de sus jefes o por ambos sistemas. Lo que intercambian no son exclusivamente bienes o riquezas, muebles e inmuebles, cosas útiles económicamente, son sobre todo gentilezas, festines, ritos, servicios militares, mujeres, niños, danzas,

\footnotetext{
${ }^{13}$ Franz Boas, geógrafo alemán, padre de la antropología cultural estadounidense. Realizó su tesis doctoral entre los inuit de Groenlandia y los koyukon en Alaska. Su labor ulterior permitió el desarrollo de la escuela particularista histórica y su labor más importante en el análisis del sistema Potlatch entre los Kwakiutl, Haida, Tsimshian; del noroeste de Norteamerica y la Isla Vancouver.. Fue el mentor de la escuela de cultura y personalidad que fundaran sus discípulos Magaret Mead, Ruth Benedict, Robert Redfield, Clyde Kulckhom y Melville Herskovitz; basados en el relativismo cultural.
} 
ferias, en las que el mercado ocupa solo uno de los momentos, y en las que la circulación de riquezas es sólo uno de los términos de un contrato mucho mas general y permanente. Estas prestaciones y contraprestaciones nacen de forma más bien voluntaria por medio de presentes y regalos, aunque en el fondo sean rigurosamente obligatorias bajo pena de guerra privada o pública. Nuestra idea es el llamar a todo esto sistema de prestaciones totales.....Hay prestación total en el sentido de que todo el clan contrata por todos, por todo lo que posee y por todo lo que hace, por medio de su jefe. Esta prestación está revestida para el jefe de un aspecto agonizante muy señalado. Es a su vez usuaria y suntuaria y sobre todo una lucha entre notables con el fin de asegurar entre ellos una jerarquía que posteriormente beneficia al clan" (Mauss, M 1925: 3).

Un sistema de intercambio de prestación total supone reciprocidad en el dar y recibir, de allí que el intercambio es de dones. Específicamente lo que se intercambia no es solo la materialidad sino el espíritu de quien/es dona/n las cosas, de allí la obligación de devolver; pues al no hacerlo el espíritu y su esencia permanece con quien ha recibido el don. Esta presencia que espera ser devuelta posee un lado negativo que se acrecienta al no cumplirse la obligación con el paso del tiempo. Cuestión que involucra no solo a quien recibe personalmente, sino a quienes representa, cayendo en desgracia el clan, la tribu, la familia correspondiente por las generaciones correspondientes. Por tanto no devolver, o devolver en poca cuantía, supone la guerra y el deshonor; lo que a estos niveles implica la des-afiliación que es el castigo mayor, la exclusión, el ser considerado no persona, no parte, no gente.

Mauss llega a diferenciar en el haus (el espíritu de las cosas) el tonga y el oloa, el espíritu femenino y el masculino, las cosas poseen esencias espirituales diferenciadas por género, lo cual involucra que deben ser trocados por sus contrarios, incluso se heredan por vías uterinas o masculinas; de tal forma que al trocar bienes muebles o inmuebles, personas (mujeres y-o niños), se intercambian con ellos espíritus femeninos o masculinos en cuya circulación puede observarse la línea de herencia de la propiedad y el ejercicio de la crianza a nivel colectivo, pues no necesariamente el padre/madre biológico/a ejerce el rol de la crianza.

En el noroeste norteamericano, tradicionalmente los jefes clánicos organizaban potlatch una vez al año con la intención de iniciar a los jóvenes, consumar casamientos, realizar funerales o agradecimientos por buen año alimentario. Ofrecer un potlatch a otra tribu, o fratría, que podía durar unos 5-6 días, suponía la preparación de toda la colectividad a fin de ofrendar regalos (máscaras, elementos de madera tallada, mantas de pieles, comidas diversas, elementos suntuarios de 
cobre, etc.). En este periodo de tiempo la comunidad invitada se alojaba en las viviendas de la que alojaba. La entrega máxima suponía incluso la quema de objetos valiosos. El potlatch contempla que la comunidad agasajada deberá realizar otro potlatch a quien fuera su anfitriona en un periodo de tiempo prefijado, tendrá mayor prestigio quien ofrende más, ya sea a los vivos o a los muertos con la quema de objetos.

El sistema de prestigio y estatus social está en función de los tipos de potlatch ofrendados. Este sistema de estatus se evidencia simbólicamente con la posibilidad de títulos nobiliarios, nombres autorizados a utilizar, danzas permitidas de ejecutarse, entre otros. En Canadá desde 1884 a 1951 se prohibió la festividad dado que las comunidades relegadas a las reducciones llevaron al potlatch a su máxima expresión, destruyendo aldeas completas. El proceso de asimilación fue sumamente violento como en el resto de América; lo que cabe aquí señalar es que al habérselos enajenado de sus tierras, haberlos reubicado, no dejarlos sembrar, cazar ni pescar en sus antiguos dominios, las comunidades vieron su sistema de status destruido, sus mundos simbólicos imposible de recrearse en la cotidianeidad de los intercambios, pues ya no había objetos plausibles de contener los haus. La obligación de dar y recibir se vio imposibilitada; con ello desaparecía el mundo de estas comunidades. A fin de disciplinar a las poblaciones los sistemas estatales diseñaron orfanatos-escuelas para los niños hijos de estas comunidades generando a su vez que en las reducciones sólo quedaran ancianos y adultos, de esta manera se aseguró la desaparición de las costumbres culturales, hecho que se observa inicialmente con el olvido de las lenguas nativas.

\section{3. La economía como sistema constitutivo de expresión identitaria}

Mauss destaca que en las comunidades estudiadas, la economía no es solo toma de decisiones para la supervivencia material sino para la supervivencia mental, nosotros diríamos hoy supervivencia simbólica. Más adelante, un autor como Maurice Godelier (1974), al analizar a la comunidad Baruya, que presenta como moneda de intercambio barras de sal, encuentra que el intercambio también implica historia, y con ello identidad.

"Se comprende entonces, por qué, en algunas cabañas baruya se hallan suspendidas sobre el hogar barras de sal viejas que tienen casi una generación, ennegrecidas por el hollín y desecadas. Por "nada en el mundo" su propietario querría cambiarlas o consumirlas, porque constituyen para él el símbolo de una amistad desaparecida, o de un pacto sellado con enemigos, lenguaje mudo que 
relata en cada instante presente lo que el pasado no debe envejecer. No sirve, por tanto, ni para comer, ni para trocar, ni para dar. Ya sólo son "buenas para pensar" (Godelier, 1974:298).

La toma de decisiones económicas supone pues una serie de razonamientos vinculados a un complejo de sistemas jurídicos, parentales, de estatus y prestigio, religiosos. Es así que Mauss encuentra referencias a estos hechos en la cotidianeidad de eventos en la sociedad occidental. Podríamos citar aquí, la dote de la novia, la festividad de los 16 o de los 15 años para las mujeres, el matrimonio, el bautismo y la elección del compadrazgo correspondiente, que implican dar y ofrecer para ubicarse en un estatus determinado socialmente, que nos sitúa en la cartografía social y posibilita luego ciertas alianzas matrimoniales, ciertos accesos a bienes muebles e inmuebles, ciertas líneas hereditarias, la vinculación con ciertos sistemas de producción, distribución y consumo; nos coloca en un mapa de obligaciones y derechos, donde ser parte de un mundo simbólico supone constituirse junto a ese mundo. La identidad constituida no solo por la pertenencia, el sentirse parte de; sino por qué los otros me ubican en cierto espacio social. Para que el proceso identitario se constituya precisa de este doble reconocimiento por parte del individuo y sus referentes. Por tanto el sistema económico posibilita y da lugar -en estos contextos- al proceso identitario.

En este sentido, analizar los sistemas económicos de las comunidades originarias con una mirada antropológica facilitó comprender que la economía no solo suponía el sistema de producción, circulación y consumo de ciertos bienes; sino que implicaba sistemas jurídicos, de parentesco, de estatus, religiosos que justificaban discursivamente esa organización; y que tal conjunción de sistemas constituía mapas geográficos ${ }^{14}$, mapas de actores, circuitos de estatus, relaciones entre los vivos y los muertos.

En fin, el diálogo entre Antropología y Economía abría nuevas formas de explicación a comportamientos que en algún momento se catalogaron de irracio-

\footnotetext{
${ }^{14}$ Los mapas son convenciones colectivas, de allí que con la desaparición de los territorios de caza, pesca, siembra o ganadería, las comunidades vieron desaparecer su historia, pues el hito geográfico resulta mojón de memoria colectiva. A este respecto puede consultarse el trabajo de sobre los inuit en Alaska y de cómo la desaparición de los mapas geográficos inuit delataban la pérdida de las remembranzas de los antepasados, pues cada hito geográfico derivaba en un nombre relativo a una hazaña del pueblo, al renombrarlas y enajenarlas se perdía vinculación en el espacio-tiempo. Los inuit debieron dejar de pescar y cazar para convertirse en trabajadores asalariados de la empresas petroleras en las costas de Canadá y Groenlandia, esta asimilación derivó en el incremento del alcoholismo, los suicidios, y la violencia doméstica
} 
nales, como pudiera ser la quema de aldeas completas por sus propios habitantes, o el intercambio del kula de collares y brazaletes desgastando a las comunidades anualmente y dejándolas sin alimento. Hasta la aparición de los trabajos de Malinowski, Mauss y Boas, estas comunidades adjetivadas como salvajes, primitivas eran justificadamente reducidas y civilizadas. A partir del conocimiento de estas racionalidades fue posible entonces explicar el impacto que generaba en las vidas cotidianas de los nativos el hecho de reconvertir sus sistemas de producción económica hacia los modos de producción capitalistas de los estados nacionales.

De allí en más, los especialistas comenzarán a analizar los sistemas de producción, circulación y consumo de bienes, con categorías emic ${ }^{15}$. Intentando desligarse de presupuestos occidentales tales como la noción de propiedad privada, fuerzas de trabajo, moneda, mercado, y buscando situar en contexto, los conceptos claves que se evidencian en cada uno de los espacios de intercambios.

La Antropología económica surgía como rama disciplinar, con un objeto de estudio particular, con un fundamento académico y político; y se vio ahora en la disyuntiva de generalizar o singularizar. Allí pues descansa la controversia formalistas -sustantivistas, la cual será materia de análisis por nosotros en otra oportunidad.

\section{REFERENCIAS BIBLIOGRAFICAS}

Arribas V y Rosato A., (2008), Antropología del consumo: de consumidores, usuarios y beneficiarios Antropofagia .

Balazote, A y Trinchero, H (2007). “Antropología económica. Comentarios sobre su surgimiento como disciplina y su expresión en Argentina” en Revista Relaciones de la Sociedad Argentina de Antropología XXXII, Buenos Aires.

Douglas M., (1986), ¿Cómo piensan las instituciones? Edit Paidos Madrid Douglas, M., (1996), La aceptabilidad del riesgo según las ciencias sociales, Paidós Buenos Aires

Douglas, M. y Isherwood, B., (1990), El mundo de los bienes. Grijalbo. México.

\footnotetext{
${ }^{15}$ El concepto emic, proviene etimológicamente de la palabra fonémica, y supone que las categorías que el investigador toma resultan provenientes directamente del contexto empírico, esto se opone a las categorías etics que derivan de fonética y que supone aquellas categorías dadas por el investigador con antelación a su inmersión al referente empírico. Quien primero acunara esta diferenciación fue el antropólogo estadounidense Marvin Harris. Podemos ejemplificar diciendo emic: Kula; etic intercambio
} 
García Canclini, N., (1990), Culturas hibridas: Estrategias para entrar y salir de la modernidad. México: Grijalb

Godelier, M., (1974), Economía fetichismo, y religión entre sociedades primitivas edit Paidos Madrid

Godelier M., (1976), “Es posible la antropología económica?” en Antropología y Economía, edit Anagrama Barcelona pp 279-334

Herskovits, M., [1940] 1952, Antropología económica. Estudio de Antropología Comparada. FCE. México D.F

Kaplan, D., (1976), "La controversia formalistas-sustantivistas de la antropología económica: reflexiones sobre sus amplias implicaciones". En Godelier, M. (Comp). En Antropología y economía. Anagrama. Barcelona.

Leclair, E., (1976), “Teoría económica y antropología económica”. En Antropología y economía. En Godelier, M. (Comp). Antropología y economía. Anagrama. Barcelona.

Lee, R., 1977 (1981), “La subsistencia de los bosquimanos Kung!”. En J. Llobera (comp). Antropología Económica. Estudios Etnográficos. Ed. Anagrama, Barcelona

Malinowski, B., (1999), "Principales características del Kula" en Los argonautas del Pacifico occidental edit Altaya pp 35-115

Mauss, M., (1989), "Sobre los dones y la obligación de hacer regalos" en Sociología y Ecología edit Tecnos, Madrid España

Meggers, B., (1973), Amazonia país ilusorio. Edit Anagrama

Polanyi, K., Arensberg, C. y Pearson, H., (1976), Comercio y mercado en los imperios antiguos. Labor. Barcelona

Rapapport, R., 1980 (1987), "Ritual, ecología y sistemas" en Cerdos para los antepasados. El ritual en la ecología de un pueblo de Nueva Guinea. Edit Siglo XXI, Madrid

Sahlins, M., (1974), La economía de la edad de piedra. Akal. Madrid. 